\title{
Quality improvement tools in disease management
}

\author{
Lisa E. Paddock \\ New Jersey Department of Health and Senior Services \\ Amy L. Phillips \\ Abbott Laboratories \\ Peter Chodoff \\ Thomas Jefferson University
}

\section{Follow this and additional works at: https://jdc.jefferson.edu/healthpolicyfaculty \\ Part of the Health Services Research Commons \\ Let us know how access to this document benefits you}

\section{Recommended Citation}

Paddock, Lisa E.; Phillips, Amy L.; and Chodoff, Peter, "Quality improvement tools in disease management" (2001). College of Population Health Faculty Papers. Paper 20.

https://jdc.jefferson.edu/healthpolicyfaculty/20

This Article is brought to you for free and open access by the Jefferson Digital Commons. The Jefferson Digital Commons is a service of Thomas Jefferson University's Center for Teaching and Learning (CTL). The Commons is a showcase for Jefferson books and journals, peer-reviewed scholarly publications, unique historical collections from the University archives, and teaching tools. The Jefferson Digital Commons allows researchers and interested readers anywhere in the world to learn about and keep up to date with Jefferson scholarship. This article has been accepted for inclusion in College of Population Health Faculty Papers by an authorized administrator of the Jefferson Digital Commons. For more information, please contact: JeffersonDigitalCommons@jefferson.edu. 


\title{
Quality Improvement Tools in Disease Management
}

\author{
LISA E. PADDOCK, M.P.H., ${ }^{1,2}$ AMY L. PHILLIPS, Pharm.D., ${ }^{2}$ \\ and PETER CHODOFF, M.D., M.P.H. ${ }^{2}$
}

\begin{abstract}
Disease management programs require constant monitoring to assure quality and address problems efficiently. To initiate continuous quality improvement in a disease management program, there are several methods available to identify potential problems within the program that may be affecting quality. Some common quality improvement instruments include the Plan-Do-Check-Act model, check sheets, and so forth. Whatever model is used, Statistical Process Control using flow charts, histograms, Pareto diagrams, scatter diagrams, control charts, and cause-and-effect diagrams provides a better understanding about how the organization's processes are functioning. These tools facilitate problem recognition and allow an organization to meet established standards of quality in the most economical manner.
\end{abstract}

\section{INTRODUCTION}

$\mathrm{C}$ ONTINUOUS QUALITY IMPROVEMENT is one of the four essential components of disease management as described by Ellrodt et al. (Table 1). ${ }^{1}$ As a method to manage illness in populations, disease management programs constantly need to monitor quality to address problems immediately and to assure that the patient is always being provided with the best services in the most efficient manner.

To initiate continuous quality improvement in a disease management program, there are several methods available to identify potential problems within the program that may be affecting quality. In the past decade, healthcare has adopted many of the quality control measures for improvement that have been used for years in the manufacturing industry. Some common quality improvement instruments include the Plan-Do-Check-Act (PDCA) model, check sheets, and use of Statistical Process Control (SPC) using flow charts, histograms, Pareto diagrams, scatter diagrams, Run diagrams, control charts, and cause-and-effect diagrams. These tools facilitate problem recognition and help define the problems in detail. In addition, these tools serve as a model for the continuous quality improvement process. Table 2 outlines the different types of quality improvement tools described in this paper.

\section{QUALITY IMPROVEMENT TOOLS}

\section{Plan-Do-Check-Act (PDCA) model}

The most commonly used problem-solving tool is the Plan-Do-Check-Act model. This model is designed to provide a systematic way to evaluate potential problems. ${ }^{2}$

The first step, called the "Plan" step, is to

\footnotetext{
${ }^{1}$ New Jersey Department of Health and Senior Services, Division of Epidemiology, Environmental, and Occupational Health, Office of Cancer Control and Prevention, Trenton, New Jersey.

${ }^{2}$ Thomas Jefferson University, Office of Health Policy and Clinical Outcomes, Philadelphia, Pennsylvania.
} 
Table 1. Four Components of Disease Management

Focus on continuum of care via integrated healthcare delivery systems.

Incorporation of prevention, diagnosis, treatment, and palliation of disease principles.

The use of clinical and administrative information systems for data collection and analyses.

Continuous quality improvement methods.

identify and analyze the problem. The second step, the "Do" step, involves generating potential solutions to the problem and implementing those solutions. Both of these steps incorporate brainstorming techniques that help define the problem and determine possible reasons for the problem. Next, data collection and analysis is performed during the "Check" step. Finally, interpretation of the results and initiation of any new processes to improve the original problem are employed during the "Act" step. If success is not achieved after the initial evaluation process using the PDCA model, the model should be adapted and the process repeated until the problems have been solved.

An example of a PDCA model is shown in Table 3. In this example, the PDCA model is used to evaluate low attendance at a diabetes disease management program. As you can see, this model provides a systematic method for identifying a problem, solving that problem and ultimately, improving the overall quality of the program.

\section{STATISTICAL PROCESS CONTROL (SPC)}

Statistical Process Control is a set of tools that utilizes mathematical principles to analyze the processes that constitute an organization's function. ${ }^{3,4}$ This allows an organization to meet established standards of quality in the most economical manner. The key analytic tools that are used are: run charts, control charts, cause and effect diagrams, histograms, Pareto diagrams, scatter diagrams, and flow charts. These tools identify the cause of process variation and allow for the proper remedial medicine. SPC can be thought of as the basic science of continuous quality improvement. A description of the tools is detailed below.

\section{Flow charts}

To accomplish continuous quality improvement in the healthcare industry, we must first understand its processes. Compared to manufacturing, the service industry's processes are more hand-offs and more complex. Flow charts provide a visualization of a process by the use of standard symbols that represent the beginning, end, decision points, and flow of activities. Fig. 1 illustrates the symbols representing the start and end of the process, steps that involve making decisions and tasks that require documentation. Arrows are used to direct the flow of each step and circled numbers indicate that the flow chart continues on another page. These symbols, and others like them, are standard for flow charts and make interpretation of the flow chart generalizable to many different situations.

Flow charts can be either simple or complex. For example, if the purpose of a flow chart is to identify the most cost-effective method for providing a service, less detail may be needed. However, if the purpose is to identify all steps involved in performing a process, much greater detail may be warranted.

The most common type of flow chart is the process flow chart. A process flow chart is used to highlight a process and how it proceeds. ${ }^{2}$ It serves as a map of steps for completing a task using symbols. Figure 2 contains a simplistic flow chart that may be used for enrolling a pa-

Table 2. Quality Improvement Tools

Plan-Do-Check-Act

Check sheets

Statistical process control

1. Run charts

2. Scatter diagram

3. Histogram

4. Flow charts

5. Control charts

6. Pareto diagram

7. Cause-and-effect diagrams

1. Ishikawa Diagram/Fishbone

2. Affinity diagram

3. Relationship diagram 
Table 3. Plan-Do-Check-Act (PDCA) Model

Plan
Problem: Low attendance at diabetes disease
management program meetings.
Do Mail "reminder cards" to all enrollees.
Check
Reassess attendance and determine if "reminder
cards" are effective.
Act
Document improvements and continue to evaluate
attendance rates.

tient in an asthma disease management program.

Another type of flow chart is the deployment flow chart. Deployment flow charts differ from process flow charts by showing a relationship between the person doing the task and the steps in the process. $^{2}$ The deployment flow chart reads from left to right. The persons involved in the process are labeled across the top of the chart and their corresponding tasks are shown below their label. Figure 3 shows the same flow chart for enrolling patients in an asthma disease management program, but also identifies who is responsible for each task.

Once constructed, flow charts can be analyzed to determine ways of streamlining the process by eliminating steps, combining steps, or creating new steps to operate the process more efficiently.

\section{Control charts}

Every continuing process exhibits variation. Control chart theory recognizes two types of variation. ${ }^{5}$ The first type is called "common cause variation," which is random, affects all the individual values of the system being studied, and can be eliminated only by altering the system. The second type of variation is called "special cause variation," and can be attributed to an identifiable cause and eliminated by altering the identifiable cause. When there is a special cause identified, the process is said to be out of control. The terms "in control" and "out of control" do not define the quality or standard to which the process should be held, but only the type of variation present.

There are two types of errors associated with decision making about variation in a process. A Type I error $(\alpha)$ falsely concludes that the process is out of control and is called the producer's risk. A Type II error $(\beta)$ falsely concludes that a process is in control when it is not and is called the consumer's risk. Avoiding these errors prevents unnecessary expenditures of finite resources.

For example, a continuous quality improvement project examining waiting time in an emergency department has the problem of analyzing a set of data points, each one being the number of minutes between registration to being seen by a physician. If the mean waiting

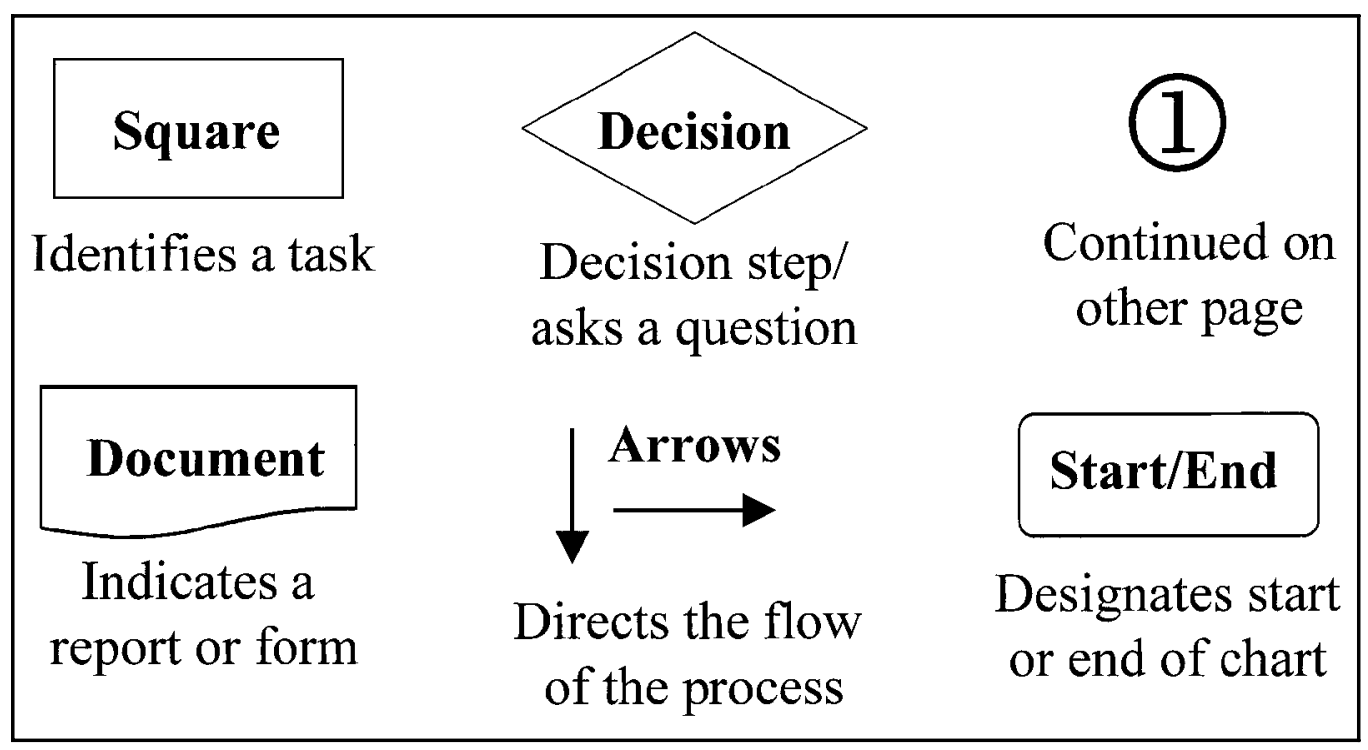

FIG. 1. Example of symbols that can be found in a Flow Chart. 


\section{Enrollment in an Asthma disease management program}

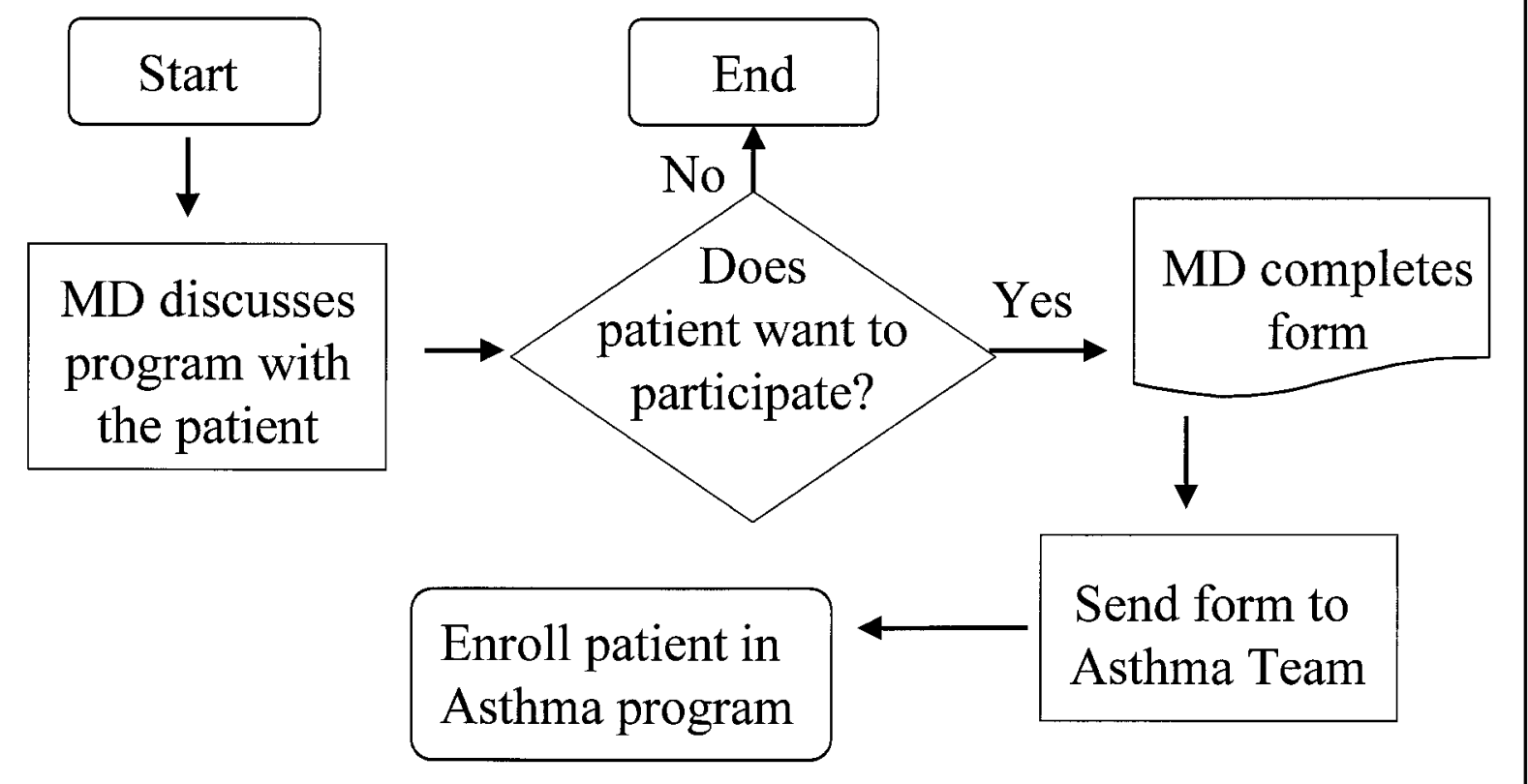

FIG. 2. Process flow chart.

time is 90 minutes, and that is too long, what is the next step? Using a control chart, we determine whether the process is in control or not. If it is in control, that tells us that the entire system needs to be redesigned. If it is out of control, we look at the limited time when it was out of control and correct only the circumstance that caused the out of control data points.

If we make a Type II error $(\beta)$, we will conclude the process is in control when it is not and expend unnecessary time and money fixing the entire process when what is necessary is to fix the limited special cause situation. A Type I error $(\alpha)$ would conclude that the process is out of control when it is not. In this case, we would repair the out of control points only, when what is necessary is to fix the entire process. This is called the producer's risk because the provider of the service has not corrected the defect in the process.

\section{Pareto diagram}

A Pareto diagram is a simple bar chart that ranks related measures in decreasing order of occurrence. ${ }^{6}$ A cumulative percentage line for all of the events is then constructed. The number of bars that make up $80 \%$ of the whole contain most of the data from the occurrence data. The Pareto diagram is based on the idea that only a few categories contain most of the data. For example, if you were investigating the cause of medication errors in a healthcare facility there might be as many as 200 places where medications were given. Using a Pareto diagram to record the results will enable you to analyze those areas that make up $80 \%$ of the errors and reduce the number of places that need to be investigated.

\section{Case-and-effect diagrams}

Cause-and-effect diagrams illustrate the relationships between causes and the net effect. Understanding the causal structure of a problem is essential in process performance. ${ }^{7}$ Although there are many different cause and effect diagrams, three commonly used models will be detailed-affinity diagrams, relationship diagrams, and Ishikawa diagrams.

The Ishikawa diagram was developed by Professor Ishikawa of Japan in 1943. ${ }^{7}$ It is some- 


\section{Enrollment in an Asthma disease management program}

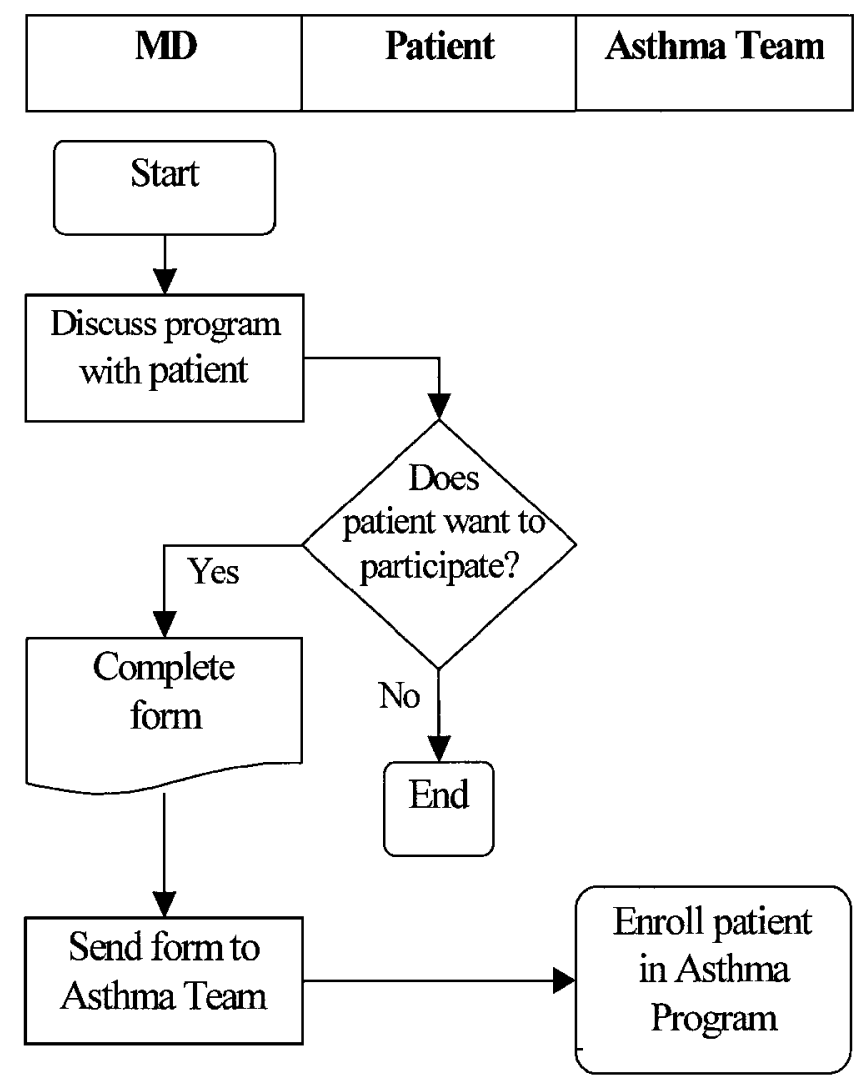

FIG. 3. Deployment flow chart.

times called the fishbone diagram because of its fishbone appearance. At the head of the fishbone the problem being investigated is stated. Fanning out from the center line are the main bones of the diagram skeleton. The main bones represent the primary causal factors. Individual twigs are then inserted in a hierarchical fashion on the appropriate main bone. The graphic nature of the diagram allows groups to organize large amounts of information about a problem and pinpoint root causes. Figure 4 provides an example of an Ishikawa diagram used to create guidelines for behavioral change for patients with cardiovascular disease.

Another cause-and-effect diagram that has been used more recently is the affinity diagram. Otherwise known as the KJ method for its creator, Kawakita Jiro, the affinity diagram is most useful for gathering large amounts of data and organizing abstract thinking into groups. ${ }^{2,8} \mathrm{Un}-$ like relationship diagrams and Ishikawa diagrams, a relationship is not established. Rather, teams can discuss all of the different causes, and effects of a problem and then categorize those with similarity or affinity. By doing this, the groups can be studied individually for a better understanding of the entire problem.

There are six steps to creating an affinity diagram. First, identify a problem to be solved (problem label). Second, record factors contributing to the problem on individual cards or slips of paper. Third, group like comments together. Fourth, give each group a name, or header. Fifth, create the affinity diagram by placing the problem label at the top center of the page. Then, group headers should be listed side by side, with subgroups directly underneath. Figure 5 presents an illustration of an 


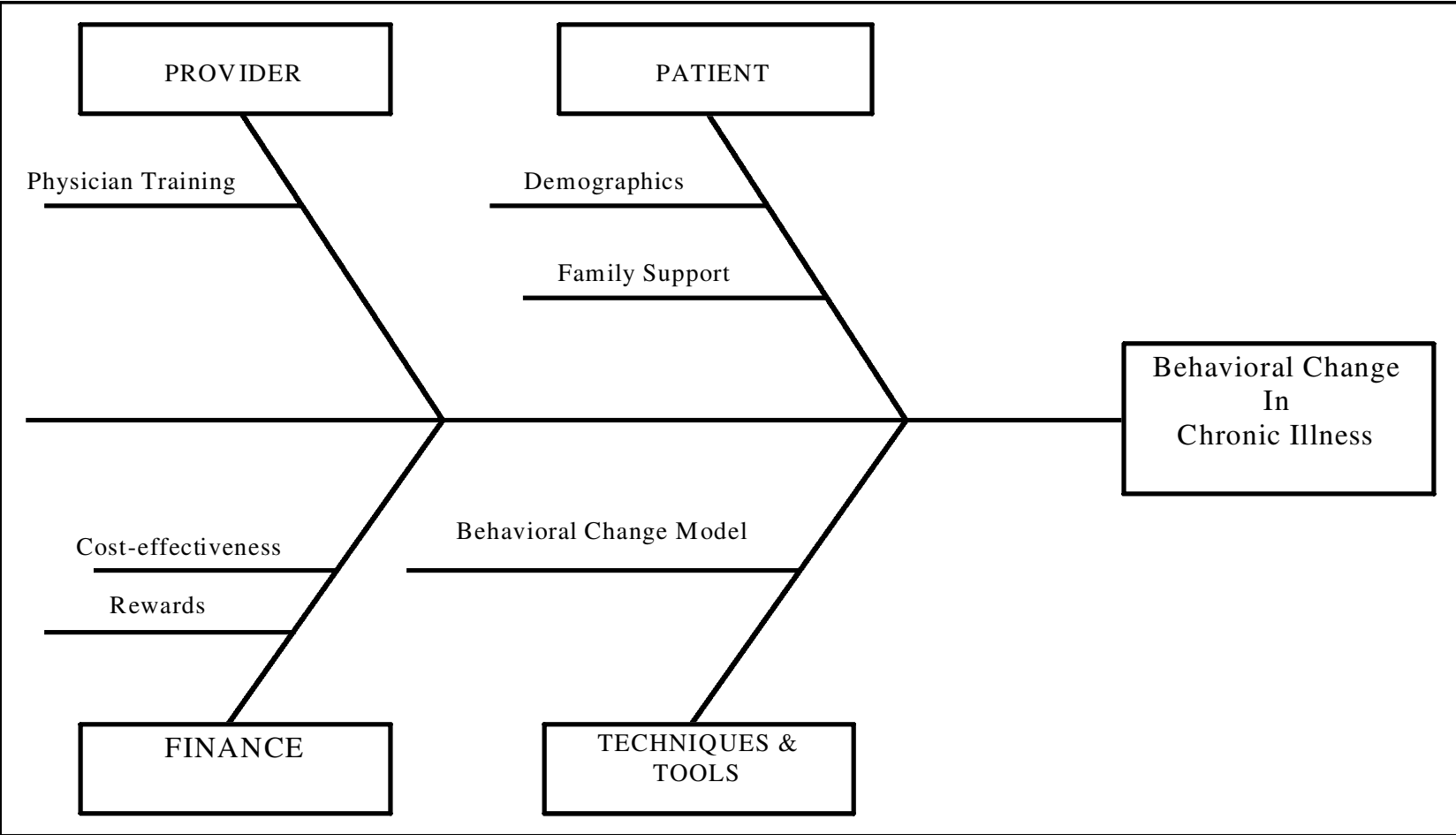

FIG. 4. Ishikawa cause and effect diagram.

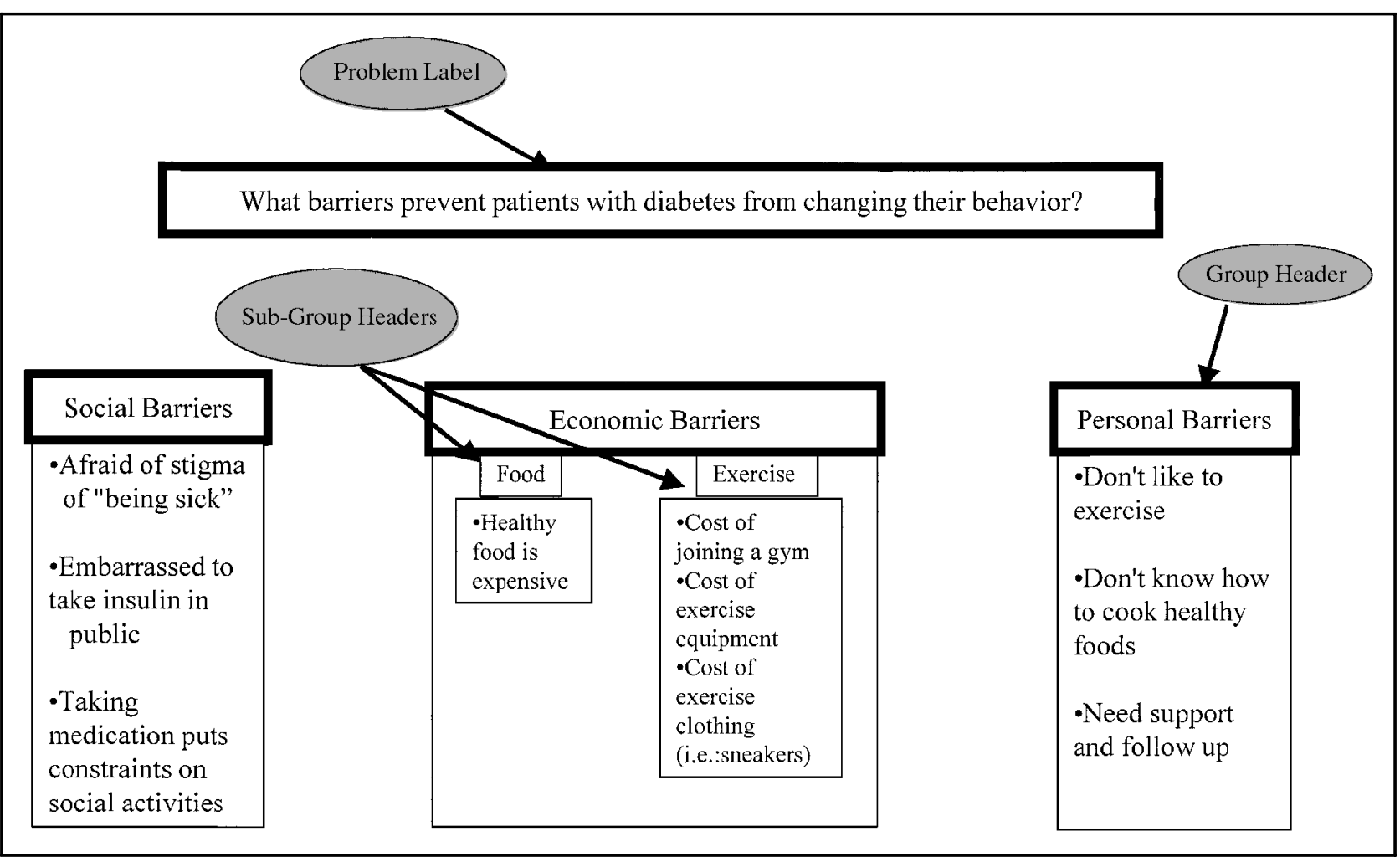

FIG. 5. An example using an Affinity Diagram. 
affinity diagram being used in a disease management program to identify barriers to patient behavior change. Using the affinity diagram, the diabetes disease management team can gain a better understanding of the difficulty of behavior change. Also, the team might identify a reason why an individual might be struggling with behavior change (e.g., cost of healthy food) and suggest methods to deal with the problem to begin the process of behavioral change.

Relationship diagrams, or relation diagrams, are tools to use when demonstrating a complex cause and effect relationship. ${ }^{2}$ While an affinity diagram aids in identifying a problem, a relationship diagram analyzes what is related to the problem. In a relationship diagram one thing might influence two or more things. This cannot easily be demonstrated by a hierarchical cause-and-effect diagram (i.e., Ishikawa) or a nonrelational diagram (affinity diagram).

A relationship diagram can be created in several steps. First, write the problem statement in the center of the page with a double circle drawn around it. Second, write all of the factors causing the problem around the outside of the circle. (This information can be fed in from an affinity diagram.) Circle each factor. Third, draw lines between items that are related, using arrowheads to demonstrate a cause-and-effect relationship. (Arrows should point away from the effect and toward the cause.) Fourth, count the number of arrows leading out of a circle (causes) and the number of arrows leading into a circle (effects). Identify the key cause factor, or the factor that has the most arrows leading out. Figure 6 demonstrates how a relationship diagram can be used to look at the causes and effects of a high rate of asthma-related emergency room (ER) visits.

\section{Run charts}

A run chart is a plot of data over time; time is plotted on the horizontal axis and the variable on the vertical axis. ${ }^{9}$ By collecting data

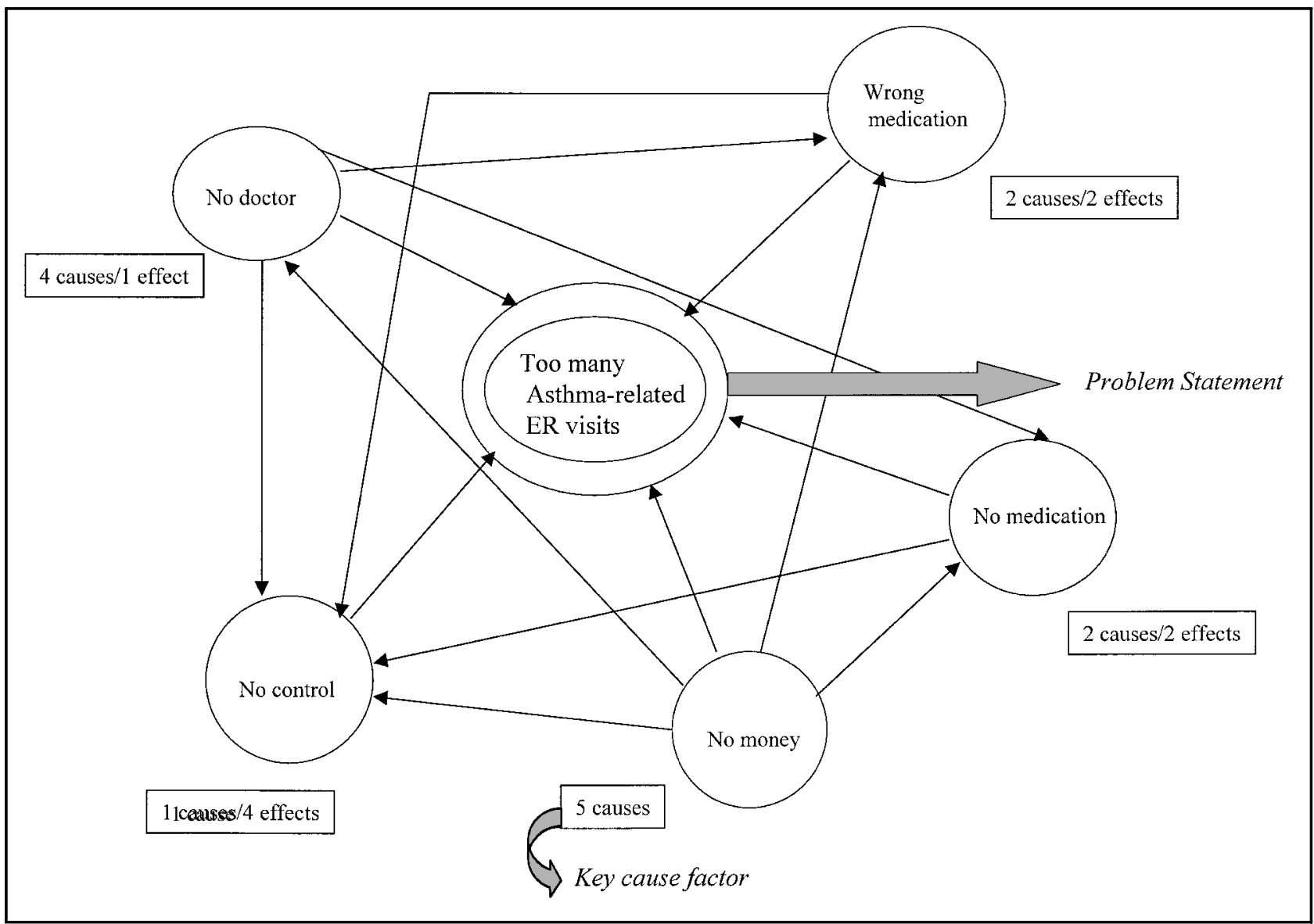

FIG. 6. An example using a Relationship Diagram. 


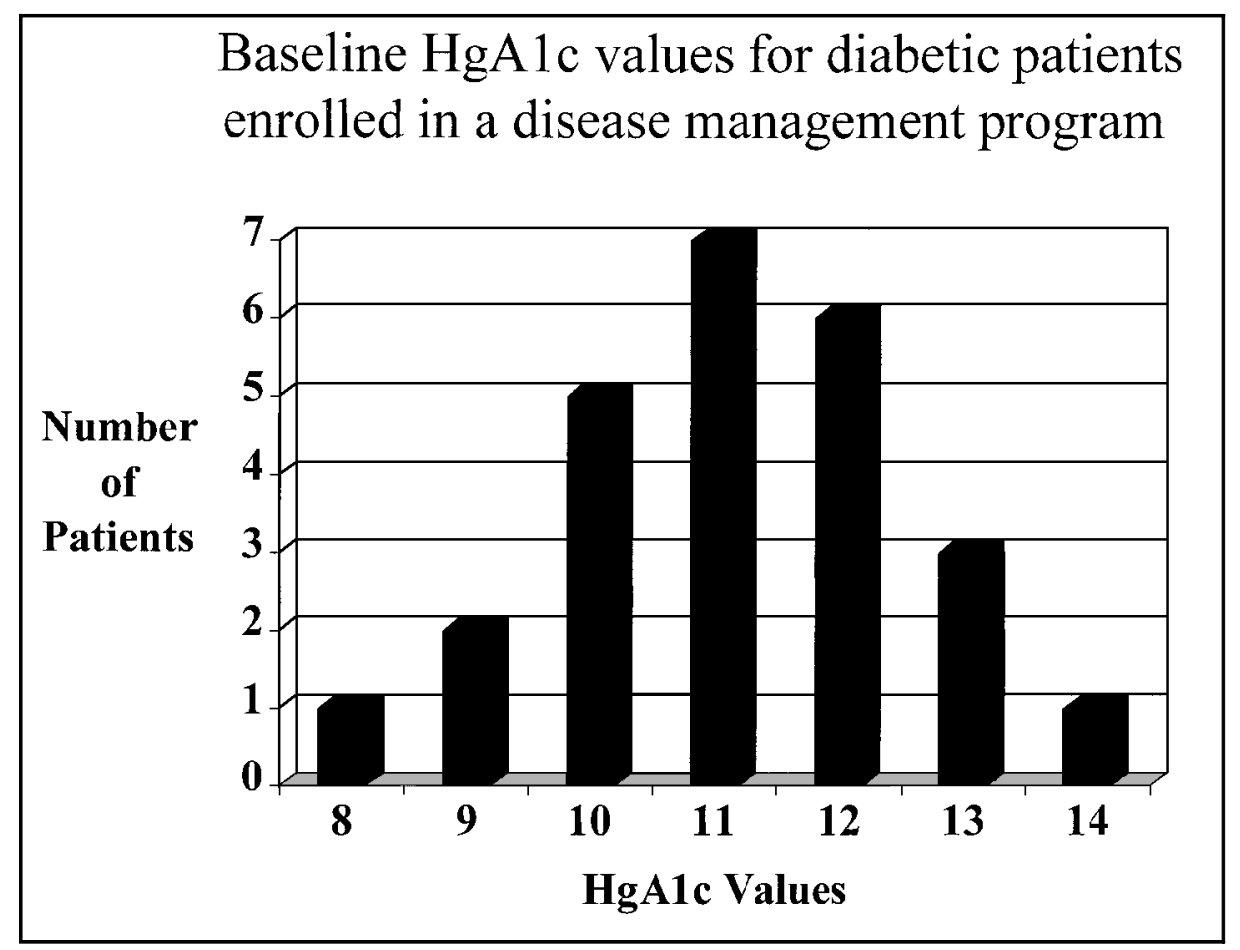

FIG. 7. An example of a Histogram.

over time, trends or patterns can be detected. If a point stands out from all the others, there is no way of knowing whether the point is really a common or special cause variation. By adding control limits, the run chart is converted into a control chart, which will enable you to tell what kind of variation is present.

The purpose of a run chart is to look at a system's behavior over time; therefore, it is critical that the data is recorded in the order it is produced and collected. For example, one might plot the number of delinquent charts per week on the vertical axis, and time in weeks on the horizontal axis. When interpreting a run chart look for seven points in a row rising or falling, a nonrandom pattern, or only one point that stands out. A run chart is really a basis for a control chart, for without completing a control chart, the type of variation will not be known. For instance, a nonrandom spike might be occurring on the first week of each month, which would correspond with the change of service of the resident staff.

\section{Scatter diagrams}

A scatter diagram helps to evaluate the relationship between two factors ${ }^{9}$; it does not provide a cause-and-effect relationship. To create a scatter diagram, a point representing a pair of measurements is plotted at the $(X, Y)$ interval. The purpose of scatter diagrams is to de-

Table 4. An Example of a Check Sheet

Collected by: Mary Jones, RN

Disease Management Program Patient Enrollment-System Wide

\begin{tabular}{lccccrrr}
$\begin{array}{l}\text { Collected by: Mary Jones, } \\
\text { Program }\end{array}$ & Jan & Feb & Mar & Apr & May & $\begin{array}{r}\text { Date: } 7 / 15 / 00 \\
\text { Total }\end{array}$ \\
\hline Maple Ridge & 12 & 10 & 15 & 7 & 10 & 11 \\
Butler County & 22 & 24 & 21 & 20 & 19 & 21 \\
Phillipsburg & 16 & 15 & 12 & 12 & 14 & 13 \\
Main Hospital & 18 & 16 & 17 & 17 & 12 & 16 \\
Total & 68 & 65 & 65 & 56 & 55 & 61 \\
\hline
\end{tabular}


termine whether there is a correlation between the two variables. By examining the pattern of the plots, a positive correlation (as $\mathrm{X}$ increases, $\mathrm{Y}$ increases), a negative correlation (as $\mathrm{X}$ increases, $\mathrm{Y}$ decreases), or no relationship can be indicated. For instance, a scatter diagram relating medication noncompliance and longterm complications may be positively correlated (i.e., as noncompliance with medication increases, there is an increase in the number of long-term complications).

Statistical programs can be used to determine more accurate correlation estimates. In conclusion, scatter diagrams can be useful in evaluating correlations between different variables of a disease management program.

\section{Histograms}

A histogram, also called a frequency distribution, is a bar graph representing the frequency of individual occurrences in classes of data. ${ }^{9}$ It is a snapshot rather than a trend over time and provides a visual representation of the data.

Histograms provide three important pieces of information about the distribution of the data, including shape (skewed right or left, random, bimodal, or symmetrical), central location (mean, median, mode), and spread (standard deviation and range). The bars in the graph have equal widths and the height of each bar corresponds with the number of data points for that group.

Figure 7 shows baseline $\mathrm{HgA} 1 \mathrm{c}$ values for diabetic patients enrolled in a disease management program. From this histogram, we can determine the central tendencies (where the majority of the data points fall) and the dispersion of the data. This information can be compared with a similar histogram containing $\mathrm{HgA} 1 \mathrm{c}$ values taken at the end of the program to assess the disease management program's impact on changes in glycemic control.

\section{CHECK SHEETS}

Check sheets are simple forms that contain fact-finding questions. ${ }^{9}$ This method allows data to be collected in a timely and consistent manner. The usefulness of the check sheet is depen- dent on the design of the form. When developing a check sheet, several aspects need to be considered, including what data should be collected, how that data will be collected and analyzed, who will be collecting the information, and where and when the data will be obtained.

For example, if you were interested in collecting total enrollment data for several diabetes disease management programs, the check sheet might resemble the one shown in Table 4 . As you can see, the data is collected in a consistent manner for each program, and the check sheet contains the name of the person collecting the data and the date the data was collected.

When a check sheet is first used, it is important to evaluate the data collection process after a short period of time to ensure that the form is collecting the appropriate information and that each person involved in the data collection is obtaining the correct information. If discrepancies are noticed in the data collection, the check sheet should be revised and all persons involved in collecting the data should be informed of the changes.

\section{CONCLUSION}

There are many tools that can be used to improve quality in a disease management program. Quality improvement methods can be used to identify a problem, organize a problem, and provide solutions. The tools described above help organize the data used in the quality improvement process. SPC can be considered the basic science of quality improvement in disease management and will provide an understanding of how a program is functioning. It will enable quality care to be given to patients in a cost-effective manner.

\section{REFERENCES}

1. Ellrodt G, Cook DJ, Lee J, et al. Evidence-based disease management. JAMA 1997;278:1687-1692.

2. Duncan, W. Total quality key terms and concepts. New York: American Management Assoc., 1995.

3. Boggs PB, Hayati F, Washburne WF, Wheeler DA. Using statistical process control charts for the continual improvement of asthma care. Joint Commission Journal on Quality Improvement 1999;25(4):163-181. 
4. Devor RE, Chang TH, Sutherland JW. Statistical quality design and control: Contemporary concepts and methods. Paramus, NJ: Prentice Hall, 1992.

5. Humble C. Caveats regarding the use of control charts. Infect Control Hosp Epidemiol 1998;19(11):865-868.

6. Clark DE, Cushing BM, Bredenberg CE. Monitoring hospital trauma mortality using statistical process control methods. J Am Coll Surg 1998;186(6):630-635.

7. Sahni, A. Seven basic tools that can improve quality. Medical Device and Diagnostic Industry 1998;4:89.

8. Lepley CJ. Problem-solving tools for analyzing system problems: The affinity map and the relationship diagram. J Nurs Adm 1998;28(12):44-50.

9. Murray SD, Murray OB, eds. Total quality tools for health care. Dayton, OH: Prime Printing, 1997.
Address reprint requests to:

Lisa E. Paddock, M.P.H.

New Jersey Department of Health and Senior Services

Division of Epidemiology, Environmental, and Occupational Health

Office of Cancer Control and Prevention 3635 Quakerbridge Road P.O. Box 369

Trenton, NJ 08625-0369

E-mail: LPaddock@doh.state.nj.us 